\title{
Helicobacter pylori-Induced DNA Damage Is a Potential Driver for Human Gastric Cancer AGS Cells
}

\author{
Yanyan Shi, ${ }^{1}$ Pan Wang, ${ }^{2}$ Yanlei Guo, ${ }^{3}$ Xiaoling Liang, ${ }^{2}$ Yuan $\mathrm{Li}^{3},{ }^{3}$ and Shigang Ding ${ }^{3}$
}

Helicobacter pylori is a major cause of gastric cancer. This study was aimed to explore the characteristic of DNA damage induced by $H$. pylori infection in gastric cancer AGS cells. After infection with $H$. pylori, the reactive oxygen species (ROS) levels in AGS cells were significantly higher than those in the uninfected cells. Cells with longer comet tails were detected after infection with $H$. pylori. The number of apurinic/apyrimidinic endonuclease 1- and phosphorylated H2AX-positive cells was significantly increased compared with the number of negative control cells. The expression of pChk1 and pChk2 was significantly upregulated by H. pylori infection. Cell growth was inhibited after H. pylori infection. All these results were dose dependent. The cell alterations were more significant upon infection with $H$. pylori at a multiplicity of infection (MOI) of 100:1 than at an MOI of 50:1. H. pylori infection can induce DNA single-strand breaks, DNA double-strand breaks, and cell cycle checkpoint activation after ROS generation in the gastric cancer cell line AGS, which is a potential driver for gastric cancer.

Keywords: Helicobacter pylori, gastric cancer, cell, DNA strand breaks, cell cycle checkpoint activation

\section{Introduction}

$\mathbf{G}$ ASTRIC CANCER IS ONE of the most common cancers in the world (Tan and Yeoh, 2015). Despite a steady decline in gastric cancer incidence and mortality rates observed in developed countries for the past 50 years, gastric cancer is still a considerable global health burden (Torre et al., 2015; Ajani et al., 2017). The incidence rate of gastric cancer is highest in Eastern Asia, including China (Torre et al., 2015). China contributes $\sim 40 \%$ of new cases of gastric cancer around the world every year (Torre et al., 2016). Primary prevention is considered to be a particularly effective way to fight against cancer. Investigation of the mechanisms of risk factors is extremely important for appropriate prevention strategies and prioritization of cancercontrol planning (Vineis and Wild, 2014).

Helicobacter pylori as an infectious agent is a major risk factor for gastric cancer and is the most important infectious agent worldwide (Plummer et al., 2016). Approximately $75 \%$ of gastric cancer cases are induced by $H$. pylori infection (Plummer et al., 2015). The International Agency for Research on Cancer has classified $H$. pylori as a group I carcinogen that causes gastric cancer in humans (1994). $H$. pylori eradication is beneficial for prevention of gastric cancer (Choi et al., 2018; Mera et al., 2018). H. pylori is a gram-negative spiral organism that colonizes gastric surface mucous cells and resides in the mucous layer (Steer, 1985). $H$. pylori infection causes inflammatory responses in the host that lead to chronic gastritis and the development of peptic ulcer disease and gastric cancer (Graham and Fischbach, 2010). The risk of gastric cancer is three to six times higher in individuals infected with $H$. pylori than in uninfected individuals (Kim et al., 2011). The discovery of $H$. pylori has revolutionized the practice of gastroenterology, and Correa's multistep cascade theory is a leading factor (Wroblewski and Peek, 2007; Plottel and Blaser, 2011; Rugge et al., 2016). Our previous studies have also shown an association between $H$. pylori infection and development of gastric cancer (Shi et al., 2013; Liu et al., 2015). However, the underlying mechanisms of $H$. pylori's role in the development of gastric cancer are complex and unclear.

Gastric tissue is particularly sensitive to reactive oxygen species (ROS) (Chaturvedi et al., 2015). The research on ROS started around 1956 with the finding that $2 \%$ of the oxygen used by the respiratory chain can be released and

\footnotetext{
${ }^{1}$ Research Center of Clinical Epidemiology, Peking University Third Hospital, Beijing, P.R. China.

Departments of ${ }^{2}$ Obstetrics and Gynecology and ${ }^{3}$ Gastroenterology, Peking University Third Hospital, Beijing, P.R. China.
}

(C) Yanyan Shi et al. 2019; Published by Mary Ann Liebert, Inc. This Open Access article is distributed under the terms of the Creative Commons Attribution Noncommercial License (http://creativecommons.org/licenses/by-nc/4.0/) which permits any noncommercial use, distribution, and reproduction in any medium, provided the original authors and the source are credited. 
transformed into a superoxide radical anion $\mathrm{O}_{2}{ }^{-}$(Harman, 1956). Endogenously generated ROS can be eliminated to achieve homeostasis. Additional stimuli induce excessive production of ROS that can exceed the scavenging capacity and cause ROS to accumulate in the human body. Studies indicate that ROS affect various signaling pathways and control many cellular processes. ROS can increase metabolic, survival, and proliferation signaling and can induce oxidative DNA damage (Kruk and Aboul-Enein, 2017; Gwangwa et al., 2018). DNA damage has been demonstrated to be the culprit for tumorigenesis (Gorgoulis et al., 2005). Oxidative DNA damage is repaired to a certain extent to maintain genome integrity by the DNA repair systems of the cell, but the damage may also avoid the repair systems (Davalli et al., 2018). DNA double-strand breaks (DSBs) are the most deleterious of all types of DNA damage. Continuous formation of DNA DSBs may contribute to genomic instability and consequently to tumorigenesis (Halazonetis et al., 2008).

In this study, we investigate $H$. pylori infection-induced DNA damage response, including SSBs, DSBs, and the activation of cell cycle checkpoint in the $H$. pylori-infected gastric cancer cell line. A real-time cell proliferation assay was used to estimate cell growth rate after $H$. pylori infection. Therefore, the aim of this study is to comprehensively assess the characteristics of $H$. pylori-induced DNA damage in association with the ROS levels; the results may help to develop early intervention and targeted therapy in $\mathrm{H}$. pylorirelated gastric mucosal diseases, especially in gastric cancer.

\section{Materials and Methods}

\section{H. pylori culture}

H. pylori strain ATCC 26695 used for this study was preserved in the Key laboratory for H. pylori infection and upper gastrointestinal diseases in Peking University Third Hospital. H. pylori ATCC 26695 was cultured on blood agar plates containing $39 \mathrm{~g} / \mathrm{L}$ Columbia solid culture medium (Oxiod), 5\% (v/v) sheep blood (Curtin Matheson, Jessup, $\mathrm{MD}$ ), and the following antibiotics: $4 \mu \mathrm{g} / \mathrm{mL}$ amphotericin B (Life Tech, Carlsbad, CA), $4 \mu \mathrm{g} / \mathrm{mL}$ trimethoprim, and $4 \mu \mathrm{g} / \mathrm{mL}$ vancomycin. The plates were incubated at $37^{\circ} \mathrm{C}$ for 3 or 5 days in a microaerobic environment $\left[5 \%(\mathrm{v} / \mathrm{v}) \mathrm{O}_{2}\right.$, $10 \%(\mathrm{v} / \mathrm{v}) \mathrm{CO}_{2}$, and $85 \%(\mathrm{v} / \mathrm{v}) \mathrm{N}_{2}$ ]. Before harvesting, the $H$. pylori cultures were examined using urease tests and Gram staining. Oxidase and catalase tests were also used to ensure that the strains were not contaminated.

\section{Cell culture, culture conditions, and coculture assays}

AGS cells were cultured in RPMI1640 medium supplemented with $10 \%(\mathrm{v} / \mathrm{v})$ fetal bovine serum (HyClone, Logan, UT). AGS cells were cultured at $37^{\circ} \mathrm{C}$ in a humidified incubator at $5 \%(\mathrm{v} / \mathrm{v}) \mathrm{CO}_{2}$. After the bacterial cultures had been resuscitated on blood agar plates, H. pylori 26695 bacteria were harvested, washed three times with phosphatebuffered saline (PBS), resuspended in the cell growth medium, and diluted to a final concentration of $1 \times 10^{8}$ $\mathrm{CFU} / \mathrm{mL}$. AGS cells were plated 1 day before $H$. pylori treatment. For coculture of the cells with bacteria, cells were rinsed once with PBS and fresh growth medium was added.
The bacterial strains were then added to the cell medium at multiplicity of infection (MOI) of 50:1 and 100:1 for $24 \mathrm{~h}$.

\section{Measurement of intracellular ROS}

Intracellular ROS levels were measured using a cellpermeable fluorogenic probe. AGS cells were seeded in 6-well plates (at a density of $2 \times 10^{5}$ cells). After coculture of the cells with $H$. pylori at an MOI of 50:1 or 100:1 for $24 \mathrm{~h}$, cells were washed with PBS for three times, and then ROS levels were monitored using a $2^{\prime}, 7^{\prime}$ dichlorodihydrofluorescein diacetate (DCF-DA) molecular probe (Beyotime, Shanghai, China). The DCF fluorescence distribution in the cells was observed under a fluorescence microscope (Olympus, Japan) at $200 \times$ magnification. The DCF fluorescence was measured using a Bio-Rad 680 multilabel counter with the excitation source at $488 \mathrm{~nm}$ and emission at $525 \mathrm{~nm}$ (Bio-Rad, CA) and data were presented as fold of control.

\section{Comet assay}

Single-cell gel electrophoretic comet assay was performed under neutral conditions to detect DSBs as described previously ( Jin et al., 2016). Intact AGS cells infected with H. pylori were collected and rinsed twice with ice-cold PBS; $2 \times 10^{4}$ cells $/ \mathrm{mL}$ were combined with $1 \%$ LMAgarose at $40^{\circ} \mathrm{C}$ at a ratio of $1: 3(\mathrm{v} / \mathrm{v})$ and immediately pipetted onto the slides. For cellular lysis, the slides were immersed in a neutral lysis solution ( $2 \%$ sarkosyl, $0.5 \mathrm{M} \mathrm{Na} \mathrm{NaDTA}_{2}$, $0.5 \mathrm{mg} / \mathrm{mL}$ proteinase $\mathrm{K}, \mathrm{pH} 8.0$ ) overnight at $37^{\circ} \mathrm{C}$ in the dark, followed by washing in the rinse buffer $(90 \mathrm{mM}$ Tris-buffer, $90 \mathrm{mM}$ boric acid, $2 \mathrm{mM} \mathrm{Na}{ }_{2}$ EDTA, pH 8.5) for $30 \mathrm{~min}$. The slides were then subjected to electrophoresis at $20 \mathrm{~V}(0.6 \mathrm{~V} / \mathrm{cm})$ for $25 \mathrm{~min}$ and stained in $2.5 \mu \mathrm{g} / \mathrm{mL}$ propidium iodide for $20 \mathrm{~min}$. Images were taken with a fluorescence microscope (Olympus, Japan) at $400 \times$ magnification and analyzed by the Comet Assay IV software.

\section{Immunofluorescence microscopy}

Immunofluorescence was performed as described previously (Ma et al., 2013). In brief, $4 \times 10^{4}$ cells per well were seeded into 24-well culture plates and incubated for $24 \mathrm{~h}$ at $37^{\circ} \mathrm{C}$ in $5 \%(\mathrm{v} / \mathrm{v}) \mathrm{CO}_{2}$; the cells were then treated with the H. pylori strain at MOI of 50:1 or 100:1 for $24 \mathrm{~h}$. PBS was used to wash the cells three times. The cells were then fixed in $4 \%$ paraformaldehyde in PBS (pH 7.4) at room temperature for $30 \mathrm{~min}$. After permeabilization with $0.1 \%$ Triton X-100 at room temperature for $30 \mathrm{~min}$, cells were blocked in $1 \%$ BSA-supplemented PBS for $1 \mathrm{~h}$ and incubated overnight at $4^{\circ} \mathrm{C}$ with antibodies to apurinic/apyrimidinic endonuclease 1 (APE1) and phosphorylated $\mathrm{H} 2 \mathrm{AX}(\gamma \mathrm{H} 2 \mathrm{AX})$. After washing three times in PBS containing $0.1 \%$ Tween- 20 and $0.01 \%$ Triton $\mathrm{X}-100$ for $5 \mathrm{~min}$ each, the cells were labeled with 1:500 FITCconjugated IgG or Rho-conjugated IgG for $1 \mathrm{~h}$ at room temperature. After washing in PBS containing $0.1 \%$ Tween 20 and $0.01 \%$ Triton X-100, the cells were co-stained. Finally, the cells were examined with a fluorescence microscope (Olympus, Japan) at $400 \times$ magnification. 


\section{Western blot analysis}

Proteins related to DNA damage were detected by western blot analysis. Cells were harvested and suspended in the cell lysis buffer containing a protease inhibitor mixture and shaken on ice for $30 \mathrm{~min}$. The cell lysate was centrifuged at $15,000 \times \mathrm{g}$ at $4^{\circ} \mathrm{C}$ for $10 \mathrm{~min}$, and the supernatant was collected. The total protein concentration was measured by the Bradford method using a BCA protein assay kit. Proteins were separated by $12 \%(\mathrm{w} / \mathrm{v})$ sodium dodecylsulfate polyacrylamide gel electrophoresis and electrophoretically transferred onto polyvinylidene fluoride membranes. The membranes were blocked in $5 \%(\mathrm{w} / \mathrm{v})$ fat-free milk in Trisbuffered saline containing $0.5 \%(\mathrm{v} / \mathrm{v})$ Tween-20 at room temperature for $1 \mathrm{~h}$ and incubated overnight at $4^{\circ} \mathrm{C}$ with antibodies against pChk1, pChk2, Chk1, Chk2, or $\beta$-actin. After three washes in PBS supplemented with $0.1 \%(\mathrm{v} / \mathrm{v})$ Tween-20 for $15 \mathrm{~min}$, the membranes were incubated with a secondary antibody for $1 \mathrm{~h}$ at room temperature. Proteins were identified by scanning the membranes using an Odyssey Imager (LI-COR Biosciences).

\section{Cell growth analysis}

A real-time cell proliferation assay was conducted using the ACEA RT-CES microelectronic cell sensor system (ACEA Biosciences) to measure the numbers of living cells. This system works by measuring electrical impedance of sensor electrodes integrated on the bottom of microtiter E-plates. In brief, after coculture with $H$. pylori for $24 \mathrm{~h}$ at MOI of 50:1 or 100:1, $1 \times 10^{4}$ cells per well were seeded in E-Plate 96 and allowed to attach for $12 \mathrm{~h}$. A unitless parameter termed the cell index was derived and used to represent the cell numbers based on the measured relative changes in electrical impedance that occurred in the presence and absence of the cells in the wells. The cell index was normalized to the baseline reading at time point 0 after the attachment (Zaid et al., 2013). Cellular impedance was measured periodically every $5 \mathrm{~min}$. The electronic sensors provided a continuous and quantitative measurement of the cell index (which depends on the number of attached cells and the shape of the cells) in each well. Cell proliferation measured using the cell index was monitored for $72 \mathrm{~h}$.

\section{Statistical analysis}

Differences between two groups were analyzed using Student's $t$-test. Comparison between multiple sample sets and the control were performed using one-way analysis of variance (ANOVA) followed by the Student-NewmanKeuls (SNK) test. Data are presented as the mean \pm SD of three independent experiments. All statistical analyses were performed using the SPSS 22.0 computer software. $p$-Values that were $<0.05$ were considered statistically significant.

\section{Results}

$\mathrm{H}$. pylori-induced intracellular ROS in gastric cancer AGS cells

To gain insight into the events underlying the pathogenic mechanisms of $H$. pylori in gastric mucosa, we assayed intracellular ROS in the gastric cancer AGS cells after $H$. pylori treatment. Cells were infected with $H$. pylori strain 26695 at an MOI of 50:1 or 100:1. ROS levels were measured after treatment with the DCF-DA molecular probe. As shown in Figure 1, after infection at MOIs of 50:1 and 100:1, the ROS levels in the AGS cells were significantly higher than those in the uninfected cells $(p<0.05)$. The ROS levels were higher at an MOI of 100:1 than at an MOI of 50:1 $(p<0.05)$.

\section{$\mathrm{H}$. pylori-induced DNA single-strand breaks and DNA $D S B s$ in AGS cells}

To study whether ROS induce oxidative DNA damage in the $H$. pylori-infected cells, we performed the neutral comet assay to examine DNA damage. As shown in Figure 2, cells with longer comet tails were detected among the cells infected with $H$. pylori, but longer tails were not detected in the negative control cells, indicating that DNA damage was induced by $H$. pylori infection $(p<0.05)$. Compared with the cells infected at an MOI of 50:1, the tail moment was longer in the cells infected at an MOI of 100:1 $(p<0.05)$. To further confirm the presence of DNA damage, we examined a surrogate marker of DNA single-strand breaks (SSBs), APE1, and a surrogate marker of DNA DSBs, $\gamma \mathrm{H} 2 \mathrm{AX}$, using immunofluorescence microscopy. The data in Figure 3 indicate that the fractions of APE1- and $\gamma \mathrm{H} 2 \mathrm{AX}$-positive cells significantly increased after $H$. pylori infection versus the negative control $(p<0.05)$. Positive cells infected at MOI of 100:1 had higher levels than cells infected at MOI of 50:1 $(p<0.05)$.

\section{H. pylori-activated cell cycle checkpoint in AGS cells}

To study whether the cell cycle checkpoint was activated due to persistent DNA damage, western blot analysis was used to monitor the active status of checkpoint kinase 1 (Chk1) and checkpoint kinase 2 (Chk2) with phosphoproteinspecific antibodies. As shown in Figure 4, no active Chk1 and Chk2 was detected in the control cells. In the cells infected with $H$. pylori, Chk1 and Chk2 were activated. The expression of pChk1 and pChk2 was significantly upregulated by $H$. pylori infection. The levels of kinases were higher in the cells infected at an MOI of 100:1 than in the cells infected at an MOI of 50:1.

\section{Cell growth in AGS cells was inhibited after $\mathrm{H}$. pylori infection}

To further investigate cell growth after DNA damage, we used an ACEA RT-CES microelectronic cell sensor system to measure the cell index after infection with $H$. pylori. After $24 \mathrm{~h}$ of infection, cells were seeded in 96-well plates. As shown in Figure 5, the growth of the AGS cells was inhibited after $H$. pylori infection in a dose-dependent manner. Approximately $43 \mathrm{~h}$ after plating, the growth of the negative control cells reached a plateau. The growth rate was reduced in the cells previously infected by $H$. pylori at an MOI of 50:1 or 100:1 for $24 \mathrm{~h}$. At $\sim 60 \mathrm{~h}$ after plating, the growth of the cells previously infected at an MOI of 50:1 reached a plateau. Approximately $70 \mathrm{~h}$ after plating, the growth of the cells previously infected at an MOI of 100:1 reached a plateau. The results of the cell index measurements indicated that the cells with DNA damage induced by $H$. pylori infection might have a delay in a cell cycle checkpoint, and this leads to mitotic exit and genomic instability. 


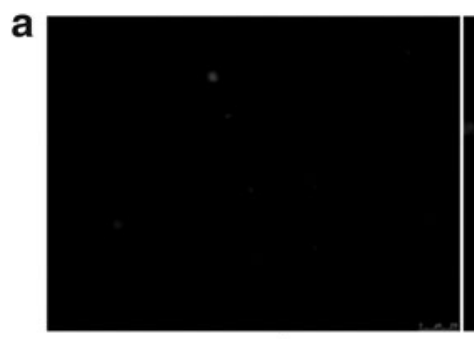

control

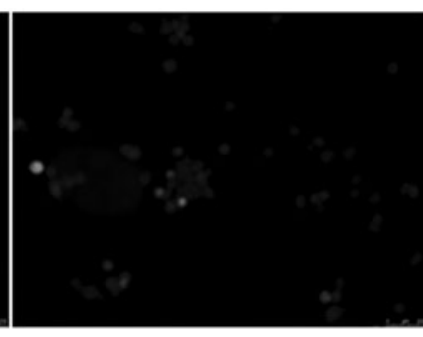

HP 50:1

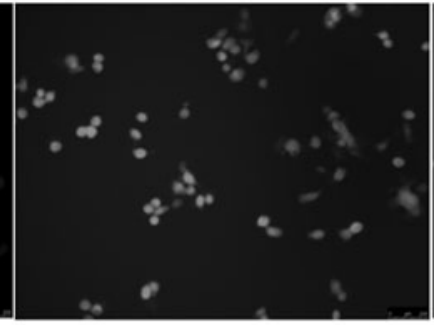

HP 100:1

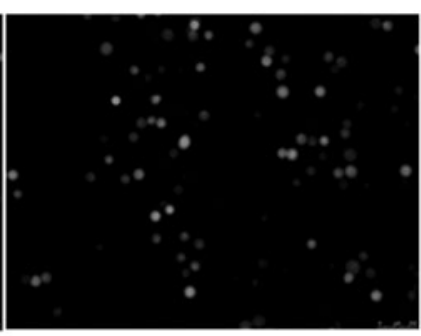

positive control b

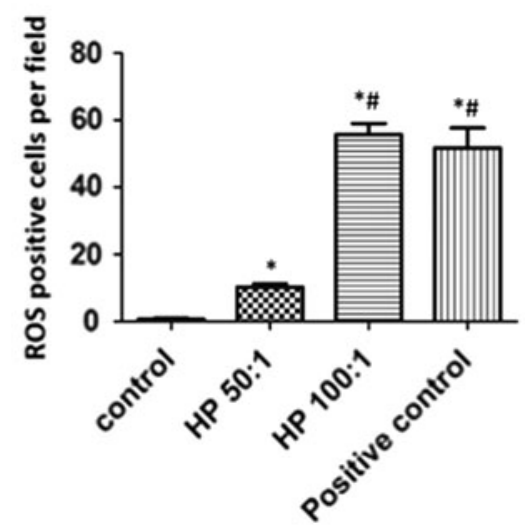

C

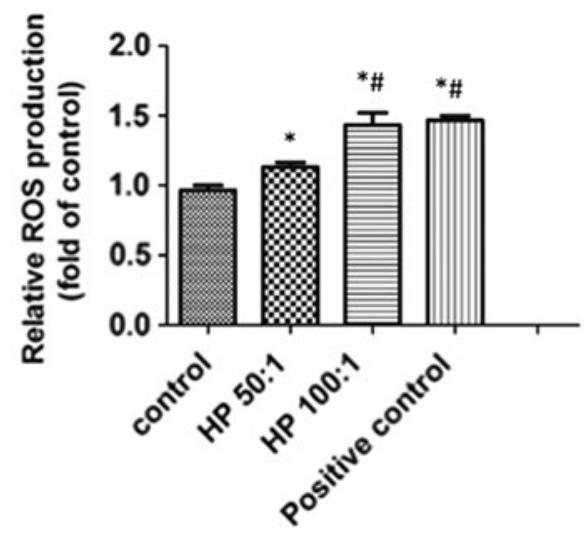

FIG. 1. Helicobacter pylori induced intracellular ROS in AGS cells. (a) After cells were cocultured with $H$. pylori at an MOI of 50:1 or 100:1, the intracellular ROS levels in the gastric cancer AGS cells were measured using DCF-DA molecular probe treatment followed by fluorescence microscopy. (b) Statistical analysis of ROS positive cells per field in three groups, including the control group without $H$. pylori infection, $H$. pylori-infected group at an MOI of 50:1, and $H$. pylori-infected group at an MOI of 100:1. (c) ROS production by measuring the level of fluorescent DCF was presented as fold of control. Data are presented as the mean $\pm \mathrm{SD}$ of three independent experiments. $* p<0.05$ was considered statistically significant versus control. ${ }^{\#} p<0.05$ was considered statistically significant versus the group with $H$. pylori infection at MOI of 50:1. DCF-DA, 2',7'-dichlorodihydrofluorescein diacetate; MOI, multiplicity of infection; ROS, reactive oxygen species; SD, standard deviation.

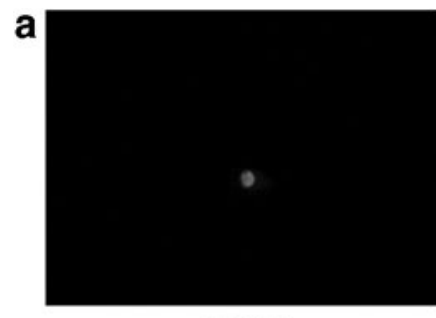

control

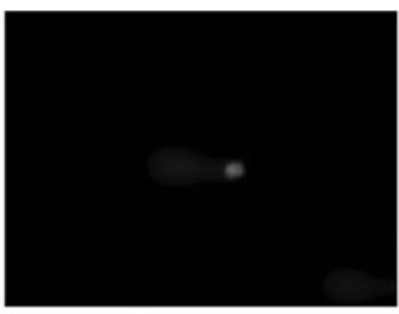

HP 50:1

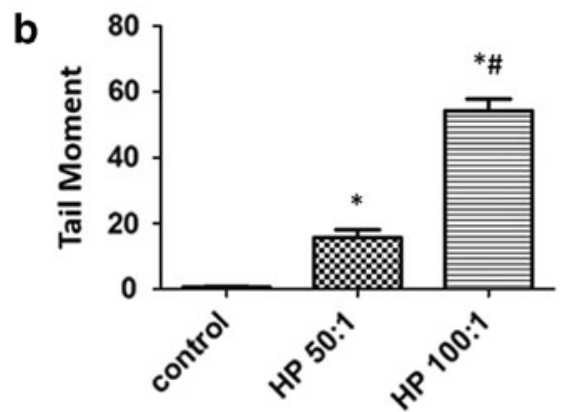

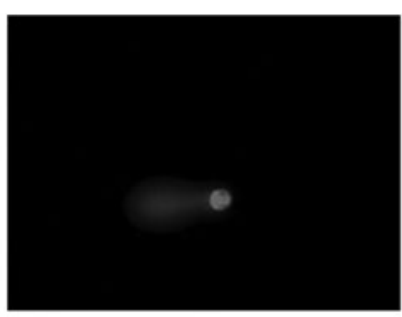

HP 100:1

FIG. 2. Helicobacter pylori induced DNA damages in AGS cells. (a) The neutral comet assay was performed to examine DNA damage after cells were cocultured with $H$. pylori at an MOI of 50:1 or 100:1. (b) Statistical analysis of the tail moment in three groups, namely, the control group without $H$. $p y$ lori infection, the $H$. pyloriinfected group at an MOI of 50:1, and the $H$. pyloriinfected group at MOI of 100:1. Data are presented as the mean \pm SD of three independent experiments. $* p<0.05$ was considered statistically significant versus control. ${ }^{\#}<0.05$ was considered statistically significant versus the group with $H$. pylori infection at MOI of 50:1. 

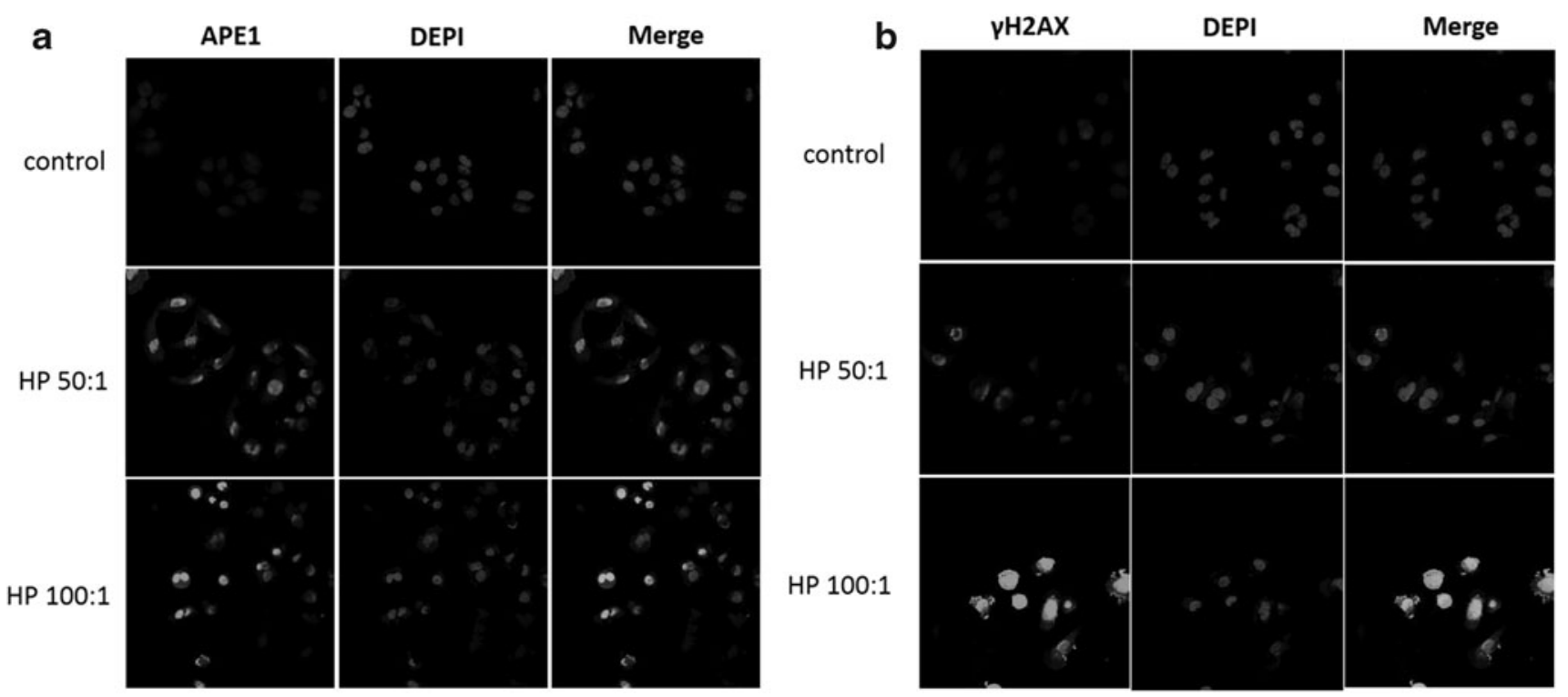

C

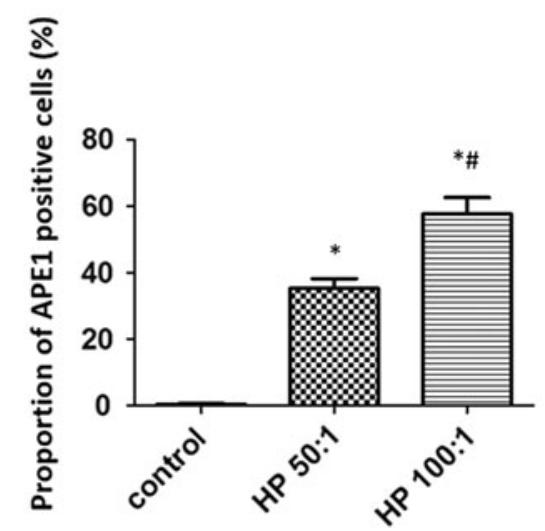

d

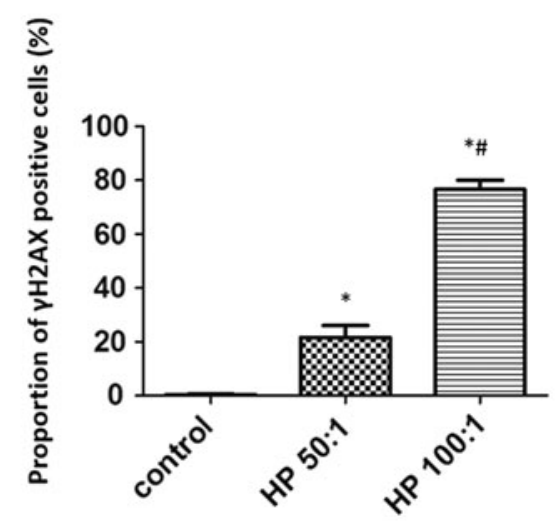

FIG. 3. Helicobacter pylori upregulated APE1 and $\gamma \mathrm{H} 2 \mathrm{AX}$ expression in AGS cells. (a, b) APE1 and $\gamma \mathrm{H} 2 \mathrm{AX}$ expression was measured using immunofluorescence microscopy after cells were cocultured with $H$. pylori at an MOI of 50:1 or 100:1. (c, d) Statistical analysis of fractions of APE1 and $\gamma \mathrm{H} 2 \mathrm{AX}$ in three groups, namely, the control group without $H$. pylori infection, the $H$. pylori-infected group at an MOI of 50:1, and the H. pylori-infected group at an MOI of 100:1. Data are presented as the mean $\pm \mathrm{SD}$ of three independent experiments. $* p<0.05$ was considered statistically significant versus control. \# $p<0.05$ was considered statistically significant versus the group with $H$. pylori infection at MOI of 50:1. APE1, apurinic/apyrimidinic endonuclease 1; $\gamma \mathrm{H} 2 \mathrm{AX}$, phosphorylated $\mathrm{H} 2 \mathrm{AX}$.

\section{Discussion}

Almost 1 million cases of gastric cancer are diagnosed each year, and $\sim 700,000$ people succumb each year to gastric adenocarcinoma, thus establishing gastric cancer as the fourth most common cancer and the second cause of cancer-related deaths in the world (Wroblewski et al., 2010). Gastric cancer is a multistep disease that can be preceded by a cascade of precancerous lesions. Multifactorial pathway has been reported to lead to gastric carcinoma, including host, bacterial, and environmental factors. The mechanisms of the development of gastric cancer are complex (Ajani et al., 2017). Further investigations of the pathogenesis can help to understand the mechanisms and might provide evidence in support of early intervention and targeted therapy in gastric cancer. $H$. pylori has been classified as a group I carcinogen that causes gastric cancer in humans, which accounts for at least $75 \%$ of gastric cancers worldwide (Plummer et al., 2015). After decades of $H$. py- lori infection, 1-3\% of patients develop gastric adenocarcinoma (Malfertheiner et al., 2012). Cohort studies from various countries have shown that $H$. pylori infection is associated with an increased risk of gastric cancer (Uemura et al., 2001; Kim et al., 2008). H. pylori eradication is beneficial for the prevention of gastric cancer development (Wong et al., 2004; Takenaka et al., 2007; Lee et al., 2016; Choi et al., 2018). H. pylori infection is one of the most important factors of etiology of gastric cancer. However, the mechanisms of $H$. pylori infection in gastric mucosal damage have not been clarified.

Studies have shown that $H$. pylori infection can trigger apoptosis of gastric epithelial cells (Correa and Piazuelo, 2008; Shi et al., 2013). Surviving cells undergo genomic events that lead to malignant transformation (David and Meltzer, 2010). Our previous studies showed that after $H$. pylori infection, numerous $H$. pylori strains adhere to the cell wall. The cell surface was damaged, the mitochondria were swollen, the mitochondrial cristae were disrupted, and 


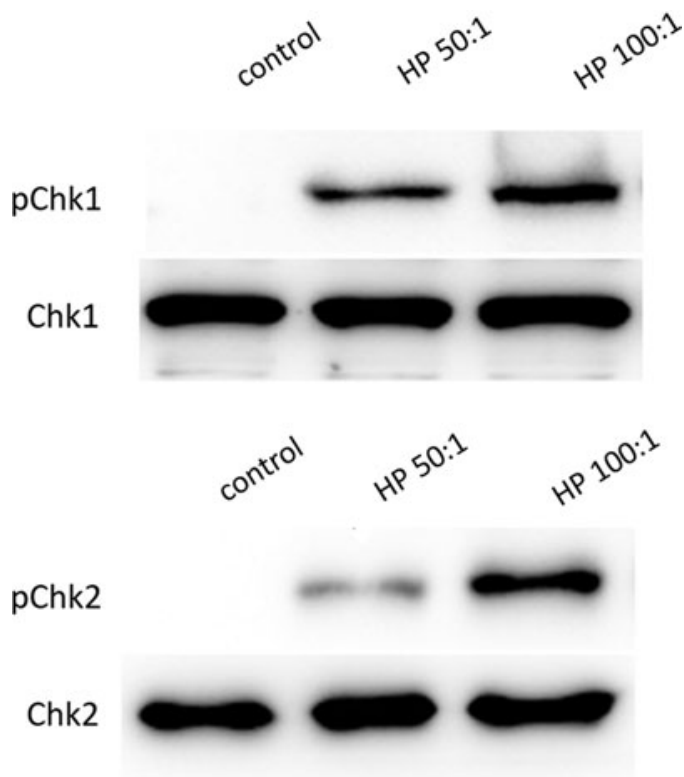

FIG. 4. Helicobacter pylori activated cell cycle checkpoint in AGS cells. Phosphorylation status of Chk1 and Chk2 in AGS cells was tested by western blotting. Total Chk1 and Chk2 were used for the loading controls.

the nuclei shrank (Shi et al., 2018), indicating that DNA damage might have occurred in the $H$. pylori-infected cells. Several effects of $H$. pylori on genomic integrity have been described. Gastric carcinogenesis requires genomic instabilities; however, the mechanisms of $H$. pylori induction of genomic instabilities remains poorly understood (Hanada et al., 2014; Koeppel et al., 2015). In this study, we extend these observations by showing that $H$. pylori induced an increase in the intracellular ROS levels, DNA DSBs, and
DNA SSBs in the gastric cancer cell line AGS, which has been routinely used in cell culture system infected by H. pylori in vitro (Wang et al., 2016; Datta et al., 2018). To comprehensively explore the occurrence of DNA damage in the $H$. pylori-infected cells, we measured ROS levels, DNA damage, cell cycle checkpoint activation, and subsequent cell growth. In our experimental setting, cell growth was assayed using a real-time cell proliferation assay that measured the cell index in real time.

Using DCF-DA molecular probe, we found that the intracellular ROS levels increased after $H$. pylori infection in a dose-dependent manner. ROS are a group of molecules produced during metabolism. Low concentrations of ROS are the fundamental signaling molecules (Gwangwa et al., 2018). Exogenous stimulation can induce excessive ROS production, which is beneficial for tumorigenesis. The resulting increase in ROS leads to depolarization of the mitochondrial membrane potential and induction of apoptosis (Dhar et al., 2018). ROS can produce multiple types of oxidative DNA damage, including SSBs. Closely spaced SSBs can form DNA DSBs (Hegde et al., 2012). The DNA damage is induced by upregulated ROS levels in tumorigenic cells; this is a double-edged sword since tumorigenesis and genomic instability are promoted by DNA mutations or can lead to cell death (Nogueira and Hay, 2013; Gwangwa et al., 2018).

In this study, we analyzed DNA damage induced in the $H$. pylori-infected cells using the comet assay. We found significantly longer comet tails in the $H$. pylori-infected cells than in the negative control cells indicating that DNA damage occurred after $H$. pylori infection. Furthermore, we examined whether $H$. pylori infection can induce APE1 and $\gamma \mathrm{H} 2 \mathrm{AX}$ accumulation in the gastric cancer cells. APE1 is a multifunctional enzyme. It is an important regulator of the cellular response to ROS and is known best for its DNA backbone cleavage activity during base excision repair.

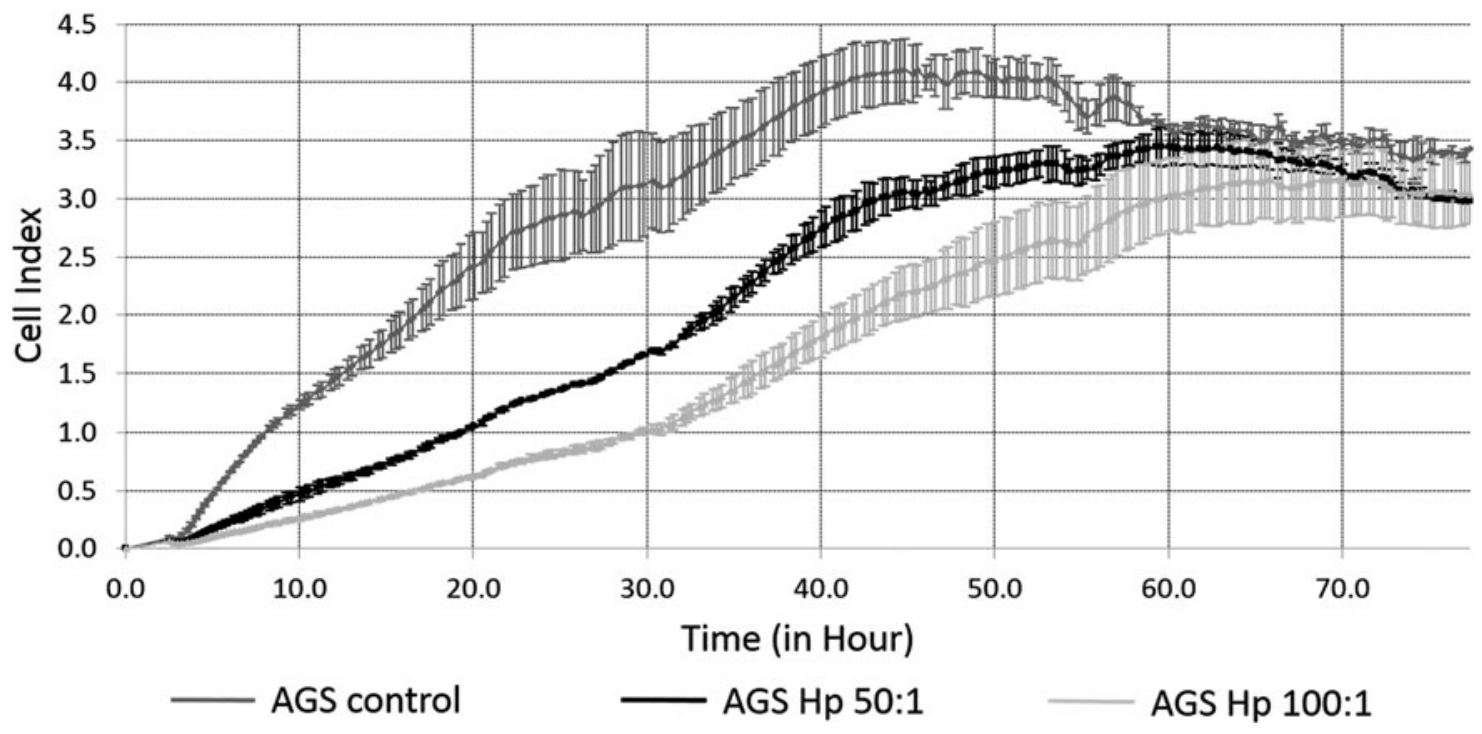

FIG. 5. Helicobacter pylori inhibited cell growth in AGS cells at the early stage after infection. Real-time cell proliferation assay using electric impedance as a measure of gastric cancer cell growth. Electrical impedance was normalized according to the background measurement at time point 0 . The results showed a significantly lower growth rate of $H$. pyloriinfected AGS cells $50 \mathrm{~h}$ after $H$. pylori infection $(p<0.05)$. 
APE1 utilizes the intrahelical DNA space to remove mismatches and DNA damage (Ilina et al., 2018). APE1 is involved in the DNA SSB repair pathway, and it can recognize DNA SSBs (Hegde et al., 2012). H2AX plays a critical role in spreading of the DNA damage signal. $\gamma \mathrm{H} 2 \mathrm{AX}$ is required for the stabilization of various DNA damage response factors at the sites of DNA lesions. Therefore, $\gamma \mathrm{H} 2 \mathrm{AX}$ is usually used as a surrogate marker of DSB presence (Li and $\mathrm{Yu}, 2013)$. Our results showed that APE1 and $\gamma \mathrm{H} 2 \mathrm{AX}$ accumulation was induced after $H$. pylori infection in a dose-dependent manner. $H$. pylori infection activates the DNA damage response pathway after oxidative DNA damage in the gastric cancer cells.

It is well known that Chk1 and Chk2 phosphorylation reflects activation of $\mathrm{Chk} 1$ and $\mathrm{Chk} 2$ that can stop the cell cycle and may result in the mitotic exit and genomic instability (Yang et al., 2010). To further investigate the cell cycle arrest, we measured the levels of active Chk1 and Chk2 in the H. pylori-infected cells using western blotting. The results showed that Chk1 and Chk2 were activated by $H$. pylori in a dose-dependent manner indicating that a cell cycle checkpoint was overactivated due to the DNA damage. The cell growth was confirmed to be inhibited using a real-time cell proliferation assay that can provide continuous measurements of the cell index. This study in vitro showed cell death after DNA damage, especially in the following $60 \mathrm{~h}$ after $H$. pylori infection. It indicated that after DNA damage induced by $H$. pylori infection, some cells underwent cell cycle arrested or cell death pathway, and other cells survived. At $70 \mathrm{~h}$, cells in three groups all reached a plateau, and the plateau was almost at the same level. Combined with literature reports, it indicated that after $H$. pylori infection, surviving cells might undergo genomic events that would lead to malignant transformation (David and Meltzer, 2010). Future studies, including molecular mechanism investigation and chronic $H$. pylori-infected animal models, should be performed to certify this hypothesis.

When DNA damage was induced and the cell cycle checkpoint was activated in the gastric cancer cells, DNA damage repair pathway was clearly activated resulting in mitotic exit, genomic instability, or cell death. These changes in the cells are beneficial for tumorigenesis. After DNA damage, cell death, apoptosis, or necrosis pathway is induced. Parthanatos, similar to apoptosis, is thought to be a protective mechanism that counteracts carcinogenesis. Meanwhile, DNA repair and damage tolerance mechanisms will be triggered, which are key cell survival pathways (Ashour et al., 2015; Stingele et al., 2015). The DNA damage response activates both prosurvival and prodeath signaling. This has been reported to be regulated complexly by many downstream proteins and it is not well understood how the cell switches between these pathways. In survival cells, mismatch repairs, genomic instability, and tumorigenesis would be promoted (Roos et al., 2016). In this study, the downstream molecular mechanisms after DNA damage were scarcely included. More studies should be carried out in the future to investigate DNA repair, and the mechanisms regulating the balance between cell survival and death in cancer biology.

In summary, this study comprehensively demonstrates that $H$. pylori infection can increase the ROS levels and induce both DNA SSBs and DNA DSBs in the gastric cancer cells; these may play an important role in gastric carcinogenesis. The results suggest that $H$. pylori-induced DNA strand breaks is a potential driver for human gastric cancer. Further studies will be performed to investigate the mechanisms of ROS and DNA damage in $H$. pylori-induced gastric carcinogenesis. The antioxidants should be chosen as a potential treatment option for $H$. pylori infection.

In this study, AGS cells were used, which have been commonly used in cell culture system infected by $H$. pylori. Normal gastric cells would be more reasonable than gastric cancer cells to explain gastric carcinogenesis induced by $H$. pylori. But there has been no mature cell culture system representing normal gastric cells at present. This problem has been paid attention to and some scientists have begun to investigate it specially and technically (Saberi et al., 2018). It is expectable in the future, a simple, consistent, and mature cell culture system representing normal gastric cells can be used to better understand $H$. pylori-induced gastric carcinogenesis.

\section{Acknowledgments}

This study was funded by the National Natural Science Foundation of China (Grant No. 81700496), the interdisciplinary medicine Seed Fund of Peking University (BMU2017MX015), and Key laboratory for Helicobacter pylori infection and upper gastrointestinal diseases, Beijing Key Laboratory (No. BZ0371).

\section{Disclosure Statement}

No competing financial interests exist.

\section{References}

(1994). Schistosomes, liver flukes and Helicobacter pylori. IARC Working Group on the Evaluation of Carcinogenic Risks to Humans. Lyon, 7-14 June 1994. IARC Monogr Eval Carcinog Risks Hum 61, 1-241.

Ajani, J.A., Lee, J., Sano, T., Janjigian, Y.Y., Fan, D., and Song, S. (2017). Gastric adenocarcinoma. Nat Rev Dis Primers 3, 17036.

Ashour, M.E., Atteya, R., and El-Khamisy, S.F. (2015). Topoisomerase-mediated chromosomal break repair: an emerging player in many games. Nat Rev Cancer 15, 137151.

Chaturvedi, R., de Sablet, T., Asim, M., Piazuelo, M.B., Barry, D.P., Verriere, T.G., et al. (2015). Increased Helicobacter pylori-associated gastric cancer risk in the Andean region of Colombia is mediated by spermine oxidase. Oncogene 34, 3429-3440.

Choi, I.J., Kook, M.C., Kim, Y.I., Cho, S.J., Lee, J.Y., Kim, C.G., et al. (2018). Helicobacter pylori therapy for the prevention of metachronous gastric cancer. N Engl J Med 378, 1085-1095.

Correa, P., and Piazuelo, M.B. (2008). Natural history of $\mathrm{He}$ licobacter pylori infection. Dig Liver Dis 40, 490-496.

Datta, C., Subuddhi, A., Kumar, M., Lepcha, T.T., Chakraborty, S., Jana, K., et al. (2018). Genome-wide mRNA-miRNA profiling uncovers a role of the microRNA miR-29b-1-5p/ PHLPP1 signalling pathway in Helicobacter pylori-driven matrix metalloproteinase production in gastric epithelial cells. Cell Microbiol 20, e12859. 
Davalli, P., Marverti, G., Lauriola, A., and D'Arca, D. (2018). Targeting oxidatively induced DNA damage response in cancer: opportunities for novel cancer therapies. Oxid Med Cell Longev 2018, 2389523.

David, S., and Meltzer, S.J. (2010). Stomach-genetic and epigenetic alterations of preneoplastic and neoplastic lesions. Cancer Biomark 9, 493-507.

Dhar, S.K., Bakthavatchalu, V., Dhar, B., Chen, J., Tadahide, I., Zhu, H., et al. (2018). DNA polymerase gamma (Polgamma) deficiency triggers a selective mTORC2 prosurvival autophagy response via mitochondria-mediated ROS signaling. Oncogene 37, 6225-6242.

Gorgoulis, V.G., Vassiliou, L.V., Karakaidos, P., Zacharatos, P., Kotsinas, A., Liloglou, T., et al. (2005). Activation of the DNA damage checkpoint and genomic instability in human precancerous lesions. Nature 434, 907-913.

Graham, D.Y., and Fischbach, L. (2010). Helicobacter pylori infection. N Engl J Med 363, 595-596; author reply 596.

Gwangwa, M.V., Joubert, A.M., and Visagie, M.H. (2018). Crosstalk between the Warburg effect, redox regulation and autophagy induction in tumourigenesis. Cell Mol Biol Lett 23, 20.

Halazonetis, T.D., Gorgoulis, V.G., and Bartek, J. (2008). An oncogene-induced DNA damage model for cancer development. Science 319, 1352-1355.

Hanada, K., Uchida, T., Tsukamoto, Y., Watada, M., Yamaguchi, N., Yamamoto, K., et al. (2014). Helicobacter pylori infection introduces DNA double-strand breaks in host cells. Infect Immun 82, 4182-4189.

Harman, D. (1956). Aging: a theory based on free radical and radiation chemistry. J Gerontol 11, 298-300.

Hegde, M.L., Izumi, T., and Mitra, S. (2012). Oxidized base damage and single-strand break repair in mammalian genomes: role of disordered regions and posttranslational modifications in early enzymes. Prog Mol Biol Transl Sci 110, 123-153.

Ilina, E.S., Khodyreva, S.N., and Lavrik, O.I. (2018). Unusual interaction of human apurinic/apyrimidinic endonuclease 1 (APE1) with abasic sites via the Schiff-base-dependent mechanism. Biochimie 150, 88-99.

Jin, Y., Xu, X., Wang, X., Kuang, H., Osterman, M., Feng, S., et al. (2016). Increasing sensitivity to DNA damage is a potential driver for human ovarian cancer. Oncotarget 7, 4971049721.

Kim, N., Park, R.Y., Cho, S.I., Lim, S.H., Lee, K.H., Lee, W., et al. (2008). Helicobacter pylori infection and development of gastric cancer in Korea: long-term follow-up. J Clin Gastroenterol 42, 448-454.

Kim, S.S., Ruiz, V.E., Carroll, J.D., and Moss, S.F. (2011). Helicobacter pylori in the pathogenesis of gastric cancer and gastric lymphoma. Cancer Lett 305, 228-238.

Koeppel, M., Garcia-Alcalde, F., Glowinski, F., Schlaermann, P., and Meyer, T.F. (2015). Helicobacter pylori infection causes characteristic DNA damage patterns in human cells. Cell Rep 11, 1703-1713.

Kruk, J., and Aboul-Enein, H.Y. (2017). Reactive oxygen and nitrogen species in carcinogenesis: implications of oxidative stress on the progression and development of several cancer types. Mini Rev Med Chem 17, 904-919.

Lee, Y.C., Chiang, T.H., Chou, C.K., Tu, Y.K., Liao, W.C., Wu, M.S., et al. (2016). Association between Helicobacter pylori eradication and gastric cancer incidence: a systematic review and meta-analysis. Gastroenterology 150, 1113-1124.e5.
Li, M., and Yu, X. (2013). Function of BRCA1 in the DNA damage response is mediated by ADP-ribosylation. Cancer Cell 23, 693-704.

Liu, L.N., Ding, S.G., Shi, Y.Y., Zhang, H.J., Zhang, J., and Zhang, C. (2015). Helicobacter pylori with high thioredoxin1 expression promotes stomach carcinogenesis in Mongolian gerbils. Clin Res Hepatol Gastroenterol 40, 480-486.

Ma, T., Chen, Y., Zhang, F., Yang, C.Y., Wang, S., and Yu, X. (2013). RNF111-dependent neddylation activates DNA damage-induced ubiquitination. Mol Cell 49, 897-907.

Malfertheiner, P., Megraud, F., O’Morain, C.A., Atherton, J., Axon, A.T., Bazzoli, F., et al. (2012). Management of Helicobacter pylori infection-the Maastricht IV/Florence Consensus Report. Gut 61, 646-664.

Mera, R.M., Bravo, L.E., Camargo, M.C., Bravo, J.C., Delgado, A.G., Romero-Gallo, J., et al. (2018). Dynamics of Helicobacter pylori infection as a determinant of progression of gastric precancerous lesions: 16-year follow-up of an eradication trial. Gut 67, 1239-1246.

Nogueira, V., and Hay, N. (2013). Molecular pathways: reactive oxygen species homeostasis in cancer cells and implications for cancer therapy. Clin Cancer Res 19, 43094314.

Plottel, C.S., and Blaser, M.J. (2011). Microbiome and malignancy. Cell Host Microbe 10, 324-335.

Plummer, M., de Martel, C., Vignat, J., Ferlay, J., Bray, F., and Franceschi, S. (2016). Global burden of cancers attributable to infections in 2012: a synthetic analysis. Lancet Glob Health 4, e609-e616.

Plummer, M., Franceschi, S., Vignat, J., Forman, D., and de Martel, C. (2015). Global burden of gastric cancer attributable to Helicobacter pylori. Int J Cancer 136, 487-490.

Roos, W.P., Thomas, A.D., and Kaina, B. (2016). DNA damage and the balance between survival and death in cancer biology. Nat Rev Cancer 16, 20-33.

Rugge, M., Genta, R.M., Graham, D.Y., Di Mario, F., Vaz Coelho, L.G., Kim, N., et al. (2016). Chronicles of a cancer foretold: 35 years of gastric cancer risk assessment. Gut $\mathbf{6 5}$, 721-725.

Saberi, S., Pournasr, B., Farzaneh, Z., Esmaeili, M., Hosseini, M.E., Baharvand, H., et al. (2018). A simple and costefficient adherent culture platform for human gastric primary cells, as an in vitro model for Helicobacter pylori infection. Helicobacter 23, e12489.

Shi, Y., Guo, Y., Zhang, T., and Ding, S. (2018). Hydrotalcite can prevent the damaging effects of Helicobacter pylori on gastric epithelial cells. Microsc Microanal 24, 277-283.

Shi, Y., Liu, L., Zhang, T., Shen, L., Liu, L., Zhang, J., et al. (2013). The involvement of Helicobacter pylori thioredoxin-1 in gastric carcinogenesis. J Med Microbiol 62(Pt 8), 12261234.

Steer, H.W. (1985). The gastro-duodenal epithelium in peptic ulceration. J Pathol 146, 355-362.

Stingele, J., Habermann, B., and Jentsch, S. (2015). DNAprotein crosslink repair: proteases as DNA repair enzymes. Trends Biochem Sci 40, 67-71.

Takenaka, R., Okada, H., Kato, J., Makidono, C., Hori, S., Kawahara, Y., et al. (2007). Helicobacter pylori eradication reduced the incidence of gastric cancer, especially of the intestinal type. Aliment Pharmacol Ther 25, 805-812.

Tan, P., and Yeoh, K.G. (2015). Genetics and molecular pathogenesis of gastric adenocarcinoma. Gastroenterology 149, 1153-1162.e3. 
Torre, L.A., Bray, F., Siegel, R.L., Ferlay, J., Lortet-Tieulent, J., and Jemal, A. (2015). Global cancer statistics, 2012. CA Cancer J Clin 65, 87-108.

Torre, L.A., Siegel, R.L., Ward, E.M., and Jemal, A. (2016). Global cancer incidence and mortality rates and trends-an update. Cancer Epidemiol Biomarkers Prev 25, 16-27.

Uemura, N., Okamoto, S., Yamamoto, S., Matsumura, N., Yamaguchi, S., Yamakido, M., et al. (2001). Helicobacter pylori infection and the development of gastric cancer. $\mathrm{N}$ Engl $\mathrm{J}$ Med 345, 784-789.

Vineis, P., and Wild, C.P. (2014). Global cancer patterns: causes and prevention. Lancet 383, 549-557.

Wang, G., Romero-Gallo, J., Benoit, S.L., Piazuelo, M.B., Dominguez, R.L., Morgan, D.R., et al. (2016). Hydrogen metabolism in Helicobacter pylori plays a role in gastric carcinogenesis through facilitating CagA translocation. MBio 7, pii: e01022-16.

Wong, B.C., Lam, S.K., Wong, W.M., Chen, J.S., Zheng, T.T., Feng, R.E., et al. (2004). Helicobacter pylori eradication to prevent gastric cancer in a high-risk region of China: a randomized controlled trial. JAMA 291, 187-194.

Wroblewski, L.E., and Peek, R.M. Jr. (2007). Orchestration of dysregulated epithelial turnover by a manipulative pathogen. Cell Host Microbe 2, 209-211.

Wroblewski, L.E., Peek, R.M., Jr. and Wilson, K.T. (2010). Helicobacter pylori and gastric cancer: factors that modulate disease risk. Clin Microbiol Rev 23, 713-739.

Yang, L., Besschetnova, T.Y., Brooks, C.R., Shah, J.V., and Bonventre, J.V. (2010). Epithelial cell cycle arrest in G2/M mediates kidney fibrosis after injury. Nat Med 16, 535-543, 531p following 143.

Zaid, T.M., Yeung, T.L., Thompson, M.S., Leung, C.S., Harding, T., Co, N.N., et al. (2013). Identification of FGFR4 as a potential therapeutic target for advanced-stage, highgrade serous ovarian cancer. Clin Cancer Res 19, 809-820.

Address correspondence to:

Yuan $\mathrm{Li}, \mathrm{MD}$

Department of Gastroenterology

Peking University Third Hospital No. 49, Garden North Road

Beijing 100191 P.R. China

E-mail: leeeyuan@aliyun.com

Shigang Ding, MD

Department of Gastroenterology

Peking University Third Hospital No. 49, Garden North Road Beijing 100191

P.R. China

E-mail: dingshigang222@163.com

Received for publication October 13, 2018; received in revised form December 2, 2018; accepted December 12, 2018. 